\title{
The Management of Maxillary Squamous Cell Carcinoma-A Retrospective Study
}

\author{
Yoav Leiser 1,2,3*, Keren Yudovich1, Michal Barak2,4, Imad Abu El Naaj 2,3,5 \\ ${ }^{1}$ Department of Oral and Maxillofacial Surgery, Rambam Health Care Campus, Haifa, Israel \\ ${ }^{2}$ Bruce Rappaport Faculty of Medicine, Technion, Haifa, Israel \\ ${ }^{3}$ The Molecular Laboratory for Oral Cancer Research, Department of Oral and Maxillofacial Surgery, Rambam \\ Health Care Campus, Haifa, Israel \\ ${ }^{4}$ Department of Anesthesiology, Rambam Medical Center, Haifa, Israel \\ ${ }^{5}$ Department of Oral and Maxillofacial Surgery, Baruch Padeh Medical Center, Puriya, Israel \\ Email: ${ }^{*}$ yleiser@gmail.com
}

Received 26 August 2014; revised 20 September 2014; accepted 15 October 2014

Copyright (C) 2014 by authors and Scientific Research Publishing Inc.

This work is licensed under the Creative Commons Attribution International License (CC BY).

http://creativecommons.org/licenses/by/4.0/

(c) (i) Open Access

\section{Abstract}

Introduction: Squamous cell carcinoma (SCC) is the predominant neoplastic tumor that occurs in the oral cavity. SCC arising from the maxillary gingiva, hard palate and maxillary alveolus is relatively rare. Since soft tissue barrier is thin, the diagnosis of cancer in these regions is usually ulcerative and invasive to the underlying bone already in the early stages of the disease. The aim of the present study was to retrospectively evaluate our data regarding the management of loco-regional lymph nodes and the efficacy of neck dissection in the clinically negative neck when maxillary squamous cell carcinoma is diagnosed. Furthermore, we wish to establish the role of prophylactic neck dissection and $\mathrm{T}$ stage from which it should be implemented. Methods: Archival records of oncological patients that were treated for SCC of the maxillary alveolus, hard palate and gingiva were collected. Overall 20 patients met the inclusion criteria, 11 men and 9 women. Average age of first diagnosis was 68 years. Results: At initial examination, 2 patients $(10 \%)$ had clinically positive lymph nodes and undergone therapeutic neck dissection. The remaining 18 patients had clinically N0 necks. Five patients $(28 \%)$ had occult positive lymph nodes following prophylactic neck dissection. One of the patients had a primary resection with no neck treatment. This patient eventually developed metastases in the neck two month post-surgery (occult disease). The overall positive lymph nodes in maxillary squamous cell carcinoma were $40 \%(8 / 20)$ with an occult metastasis rate of $33 \%(6 / 18)$. Disease specific mortality was $45 \%(9 / 20)$. Conclusion: In the present study, the majority of patients that were diagnosed with occult metastatic disease were either large tumors $(\mathrm{T} 4,60 \%)$ or with moderate to poor differentiation (mood-poor $80 \%$ ). We conclude that patients who are present with a high grade (moderate-poor) large or invasive max-

${ }^{*}$ Corresponding author. 
illary SCC (T2-T4), a prophylactic selective neck dissection (levels I-III) should be performed.

\title{
Keywords
}

\author{
Maxillary SCC, Neck Dissection, Prophylactic, Occult Metastasis
}

\section{Introduction}

Oral cavity cancer is a worldwide problem. There are 263,000 cases each year, which are estimated to cause about 127,000 deaths annually [1]. Squamous cell carcinoma is the predominant neoplastic tumor that occurs in the oral cavity. SCC arising from the maxillary gingiva, hard palate and maxillary alveolus is rare, accounts for approximately $66 \%$ of cancers of the hard palate and maxillary alveolus [2]. In these sites, SCC is usually ulcerative and invades the underlying bone in the early stage of the disease. High rates of occult metastasis to the lymph nodes are found in patients with early stage oral cavity cancer, particularly of the oral tongue and floor of mouth [3]-[6]. It is therefore recommended to perform an elective neck dissection in patients with early stage in order to reduce the risk of loco-regional lymph node disease [7] [8]. Due to the rarity of this tumor site, the evolvement of an evidence-based protocol regarding treatment is difficult. In the past, SCC confined to the maxilla was not accompanied by neck dissection, they were felt to have a lower rate of occult regional disease and have been managed by observation of regional lymphatic. Only few data exist in the literature regarding the management of loco-regional lymph nodes and the efficacy of neck dissection or radiation in the clinically negative neck. In recent years, the introduction and evolvement of superior imaging and pathological and molecular techniques has directed a higher occult metastases incidence. Despite the technological progress, no available imaging modality can detect micrometastases. Publications regarding SCC of the maxilla are scarce and management of the clinically negative neck is debatable. Recently higher rates of occult lymph node metastasis are correlated to SCC of the maxillary alveolus and palate [9]-[11]. Surgical elective management of the neck among patients who initially present with no clinical evidence of neck disease has two goals, diagnostic and therapeutic. Elective neck dissection (END) provides crucial information by permitting pathological staging. The END pathological results assist further treatment decisions (a pathohistological positive nodal involvement after supraomohyoid neck dissection will lead to extended neck dissection) and reduce unnecessary radiation, indicating where adjuvant therapy is needed and reduces the need for radical salvage neck dissection as required at the presence of delayed cervical failure [11]. The high rate of cervical nodal disease for T4 SCC supports the recommendation to perform elective neck dissection in patients with N0 [12]-[14]. Elective treatment of the neck in patients with clinically N0 and early stage (T1-2) maxillary SCC remains controversial. In a clinically positive neck, when the cervical lymph nodes are palpable or demonstrated by imaging (CT or MRI) at time of diagnosis, a modified radical neck dissection or radiation therapy is advisable. The aim of the present study is to present our experience regarding elective neck dissection preformed in Squamous cell carcinoma of the maxilla. The aim of the present study is to retrospectively investigate our data regarding maxillary squamous cell carcinoma and establish the role of prophylactic neck dissection in maxillary squamous cell carcinoma.

\section{Materials and Methods}

The presented study is a retrospective study of archival records of patients that were treated for SCC of the maxillary alveolus, hard palate and gingiva in the Department of Oral and Maxillofacial Surgery at Rambam Medical Center between the years 2000 and 2013. Inclusion criteria were adult patients that were treated for SCC of the maxilla, exclusion criteria; patients with tumors extending to the maxilla from adjacent areas (e.g., maxillary sinus, buccal mucosa and retromolar trigone) or patients with positive metastatatic disease. Initial examination included medical history, physical examination (with thorough head and neck inspection and palpation), blood tests, chest X-ray, electrocardiogram, CT-scan and biopsy. Staging was performed using the criteria for oral cancer developed by the International Union against Cancer (UICC, 2002) TNM classification, based on clinical head and neck examinations and computed tomography scanning. All patients were followed up closely with physical examination. The present work complies with the principles laid down in the Declaration of Helsinki and has been approved by the appropriate ethical committees at our institute. 


\section{Results}

The study group contained 20 patients who met the inclusion criteria, 11 men and 9 women, age of first diagnosis ranged from 40 to 85 years (average 68 years). Table 1 consists of patient characteristics, comprising of age, gender, TNM staging, nodal disease on presentation, presence of nodal metastases on neck dissection pathology and survival. The majority of patients that were diagnosed with occult metastatic disease were either large tumors (T4, 3/5, 60\%) or with moderate to poor differentiation (mood-poor 4/5, 80\%, 1/5 well-mod, 20\%) and all the patients with positive lymph nodes at initial examination were diagnosed with a T4 tumors (Figure 1). All primary tumors were operated on. Two (10\%) patients had clinically positive lymph nodes at presentation and received therapeutic neck dissection (selective neck dissection of levels I-IV). The presence of a positive lymph node at initial presentation was determined clinically by palpation or radiographically suspected on CT and fine needle aspiration (FNA) was performed. Eighteen (90\%) patients had cN0 (clinically negative nodal involvement) at presentation; four (4/18, 22\%) patients did not receive neck dissection either due to refusal by the patient or due to lack mall size (T2) and good cellular differentiation (well differentiation) at the initial biopsy. The rest of the patients, 14, (78\%) received an elective supraomohyoid neck dissection (levels I-III). Of the 18 patients with clinically N0 necks, five (28\%) had positive neck involvement ( $\mathrm{pN}+$ ) on elective neck dissection, nine (50\%) had pathologically negative lymph nodes. One of the patients had a primary resection with no neck treatment, this patient eventually developed metastases in the neck two month postsurgical ablation. This patient was treated with radiotherapy and died seven month later. The calculated occult neck disease is composed of the five $\mathrm{pN}+$ patients (from the initially cN0 group) added to the patient that developed early metastases in the neck,

\begin{tabular}{|c|c|c|c|c|c|c|c|c|}
\hline Age (years) & Gender & $\mathbf{T}$ & $\mathbf{c N}$ & $\mathbf{p N}$ & CRT & Recurrence & Differentiation & Survival \\
\hline 65 & $\mathrm{f}$ & 4 & 0 & 0 & No & Non & Well-mod & Alive \\
\hline 83 & $\mathrm{~m}$ & 4 & 0 & 1 & No & Local & Mod & Dead \\
\hline 40 & $\mathrm{~m}$ & 4 & 0 & 0 & Yes & Neck & Well & Dead \\
\hline 72 & $\mathrm{~m}$ & 4 & 0 & N/A & No & Non & Mod & Dead \\
\hline 82 & $\mathrm{f}$ & 2 & 0 & 0 & No & Non & Well & Alive \\
\hline 71 & $\mathrm{~m}$ & 2 & 0 & 0 & No & Local & Well & Alive \\
\hline 61 & $\mathrm{~m}$ & 4 & 0 & 0 & Yes & Local & Poor & Dead \\
\hline 68 & $\mathrm{f}$ & 2 & 0 & N/A & No & Non & Well & Alive \\
\hline 71 & $\mathrm{~m}$ & 4 & 0 & 1 & Yes & Non & Mod & Alive \\
\hline 84 & $\mathrm{~m}$ & 4 & 0 & 1 & Refused & Neck & Poor & Dead \\
\hline 62 & $\mathrm{f}$ & 3 & 0 & 0 & No & Non & Well-mod & Alive \\
\hline 64 & $\mathrm{f}$ & 2 & 0 & 1 & Yes & Non & Well-mod & Alive \\
\hline 69 & $\mathrm{f}$ & 2 & 0 & N/A & Yes & Neck & Well & Dead \\
\hline 71 & $\mathrm{~m}$ & 4 & 1 & 1 & Yes & Neck & Well & Dead \\
\hline 59 & $\mathrm{~m}$ & 2 & 0 & N/A & No & Non & Well & Dead \\
\hline 50 & $\mathrm{~m}$ & 3 & 0 & 0 & Yes & Non & Mod & Dead \\
\hline 77 & $\mathrm{f}$ & 2 & 0 & 0 & No & Local & Early-well & Dead \\
\hline 56 & $\mathrm{~m}$ & 2 & 0 & 1 & Yes & Non & Mod & Alive \\
\hline 81 & $\mathrm{f}$ & 4 & 1 & 2 & Yes & Local & Mod & Dead \\
\hline 85 & $\mathrm{f}$ & 4 & 0 & 0 & Yes & Non & Well & Alive \\
\hline
\end{tabular}

cN-Clinical nodal status; pN-Final Pathological nodal status; CRT-Post operative Chemo-radio therapy. 


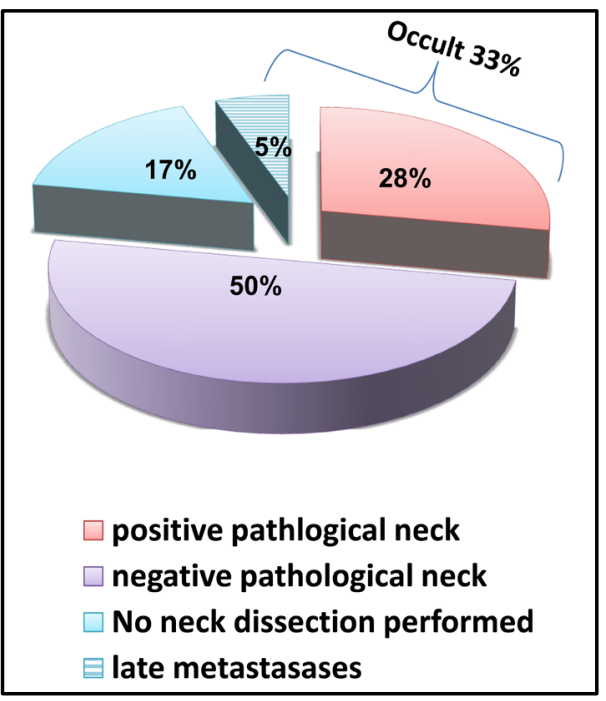

Figure 1. The distribution of the clinically NO patients group.

to make an ocuult rate of 33\% (6/18). Lymph nodes status distribution in correlation to tumor size is presented in Figure 2 (dark, clinical status, columns represent the sum of striated final pathology columns, Total no. of patients were 20). Patients with positive lymph nodes at presentation $(\mathrm{cN}+)$ were all found in $\mathrm{T} 4$ tumors. The patient that had a primary resection with no neck treatment and developed early node metastases in the neck had a $\mathrm{T} 2$ tumor. Two patients with $\mathrm{T} 2$ tumor had $\mathrm{pN}+$ positive lymph nodes on elective neck dissection. Table 2 presents the distribution of lymph nodes status and disease specific death in correlation to tumor size. Seven patients on the T4 group died, 2 patients had a local recurrence, 4 patients had recurrence in neck nodes and 1 patient died of other cause. One patient on the T3 group died from local recurrence. Two patients on the T2 group died, one patient had recurrence in neck nodes and one patient died of other cause.

\section{Discussion}

The presence or absence of cervical lymph node metastasis is considered to be one of the major prognostic factors for survival in patients with clinically negative cervical lymph nodal involvement at initial examination [15]. The clinical and pathological variables that are associated with the development of cervical lymph node metastasis have been well established in the current literature for other locations like tongue, mouth floor, and cheek [16]-[18], An incidence of 20\% - 30\% of cervical metastasis in cancer of the tongue/mouth floor has been found and is well established [16]-[18]. Yet, very few studies have been performed concerning squamous cell carcinoma of the maxilla [11]. Elective treatment of the neck in patients with clinically N0 and early stage (T1-2) maxillary SCC remains debatable due to the relative rarity of cancer of maxillary origin and lack of substantiated large scale publications. Simental et al. (2006) [11] found a 34.6\% of cervical metastasis from squamous cell carcinoma of the maxillary alveolus and hard palate. In the present study the overall positive lymph nodes rate was $40 \%(8 / 20)$ with a similar occult metastasis rate of 33\% (6/18). Our patients' disease specific mortality was found to be $45 \%(9 / 20)$. It is well established that high rate of cervical nodal disease is found in large T4 SCC tumors supporting the recommendation to perform elective neck dissection in patients that present with clinically N0 necks [12]-[14]. Recent multicentre studies on the role of neck dissection in maxillary SCC concluded that maxillary SCC exhibits an aggressive metastatic behavior, comparable with that of carcinomas of the tongue, mouth floor, and mandibular gingiva [19] [20], as a primary management strategy for patients with maxillary squamous-cell carcinomas involving the palate, maxillary gingiva, or maxillary alveolus the Beltramini et al. and the Montes et al groups recommended selective neck dissection in all patients with T2-T4 tumors and clinically negative necks. The majority of our patients that were diagnosed with occult metastatic disease were either large tumors (T4, 3/5, 60\%) or high grade with moderate to poor differentiation (mood-poor 4/5, $80 \%, 1 / 5$ well-mod, 20\%), these results support the current literature in the need for neck treatment in advanced SCC of the maxilla (T2-T4) but also in high grade cases with moderate-poorly cellular differentiation. It is well 
Table 2. Distribution of lymph node status and disease specific death in correlation to tumorsize.

\begin{tabular}{ccccc}
\hline & T1 & T2 & T3 & T4 \\
\hline Clinically negative neck & 0 & 8 & 2 & 8 \\
Pathologically positive neck & 0 & 2 & 0 & 5 \\
Disease specific deaths & & & & \\
Recurrence at primary site & 0 & 0 & 1 & 2 \\
Recurrence in neck nodes & 0 & 1 & 0 & 4 \\
Total & 0 & 1 & 1 & 6 \\
Death of other cause & 0 & 2 & 0 & 1 \\
\hline
\end{tabular}

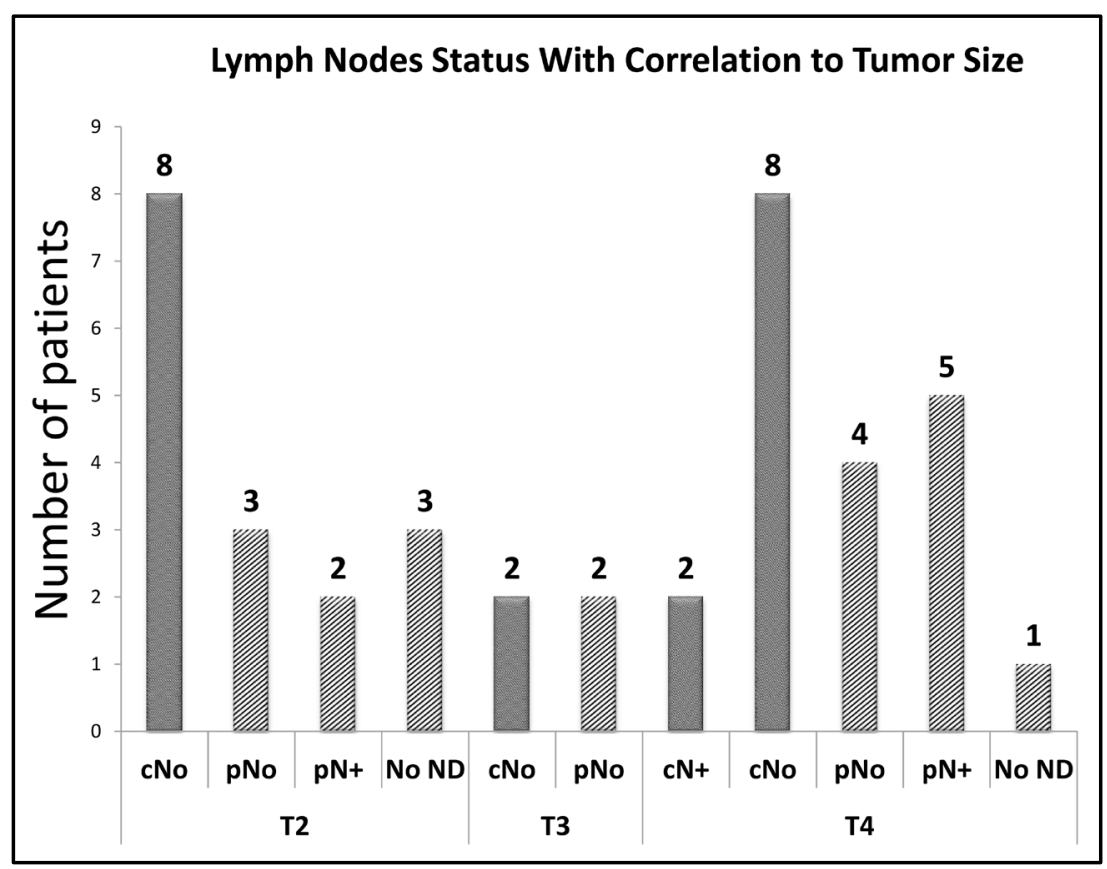

cN0-No clinical nodal; $\mathrm{cN}+$-Positive node at initial examination; pN0-No Pathological nodal; pN+—Positive pathological Nodes; No ND-No neck dissection performed.

Figure 2. Lymph nodes status with correlation to the maxillary tumor size.

known that a $15 \%$ to $20 \%$ incidence of lymph node metastases is considered the accepted threshold for elective neck dissection in other, more prevalent, sites of oral SCC [21]-[23].

\section{Conclusion}

The results presented in this study support recent publications from the multicentric groups from 2011-2012 [19] [20] and also with previous results published by Kruse and Grätz from 2009 [9]. Regarding the presented results, the main limitation of our study is the relatively low number of patients. Nevertheless, when considering the rarity of maxillary SCC, the high rate of cervical involvement is $40 \%$; which is considered above the accepted threshold for elective neck dissection. 25\% of the T2 maxillary SCC patients have cervical nodal involvement. We feel that it is well accepted that T2 and greater maxillary SCC or high grade cellular differentiation carcinomas with a N0 neck should receive a selective (I-III) neck dissection as a part of their oncological treatment. Future large scale prospective trials are needed to establish guidelines for maxillary squamous cell carcinoma treatment. 


\section{Competing Interests}

The authors declare that they have no competing interests.

\section{References}

[1] Jemal, A., Bray, F., Center, M.M., Ferlay, J., Ward, E. and Forman, D. (2011) Global Cancer Statistics. CA: A Cancer Journal for Clinicians, 61, 69-90. http://dx.doi.org/10.3322/caac.20107

[2] Petruzzelli, G.J. and Myers, E.N. (1994) Malignant Neoplasms of the Hard Palate and Upper Alveolar Ridge. Oncology (Williston Park), 8, 43-48; Discussion 50, 53.

[3] Capote, A., Escorial, V., Munoz-Guerra, M.F., Rodriguez-Campo, F.J., Gamallo, C. and Naval, L. (2007) Elective Neck Dissection in Early-Stage Oral Squamous Cell Carcinoma-Does It Influence Recurrence and Survival? Head Neck, 29, 3-11. http://dx.doi.org/10.1002/hed.20482

[4] Duvvuri, U., Simental Jr., A.A., D’Angelo, G., Johnson, J.T., Ferris, R.L., Gooding, W. and Myers, E.N. (2004) Elective Neck Dissection and Survival in Patients with Squamous Cell Carcinoma of the Oral Cavity and Oropharynx. Laryngoscope, 114, 2228-2234. http://dx.doi.org/10.1097/01.mlg.0000149464.73080.20

[5] Hicks, Jr., W.L., Loree, T.R., Garcia, R.I., Maamoun, S., Marshall, D., Orner, J.B., Bakamjian, V.Y. and Shedd, D.P. (1997) Squamous Cell Carcinoma of the Floor of Mouth: A 20-Year Review. Head Neck, 19, 400-405. http://dx.doi.org/10.1002/(SICI)1097-0347(199708)19:5<400::AID-HED6>3.0.CO;2-3

[6] Pimenta Amaral, T.M., Da Silva Freire, A.R., Carvalho, A.L., Pinto, C.A. and Kowalski, L.P. (2004) Predictive Factors of Occult Metastasis and Prognosis of Clinical Stages I and II Squamous Cell Carcinoma of the Tongue and Floor of the Mouth. Oral Oncol, 40, 780-786. http://dx.doi.org/10.1016/j.oraloncology.2003.10.009

[7] Keski-Santti, H., Atula, T., Tornwall, J., Koivunen, P. and Makitie, A. (2006) Elective Neck Treatment versus Observation in Patients with T1/T2 N0 Squamous Cell Carcinoma of Oral Tongue. Oral Oncology, 42, 96-101. http://dx.doi.org/10.1016/j.oraloncology.2005.06.018

[8] Smith, G.I., O’Brien, C.J., Clark, J., Shannon, K.F., Clifford, A.R., McNeil, E.B. and Gao, K. (2004) Management of the Neck in Patients with T1 and T2 Cancer in the Mouth. British Journal of Oral and Maxillofacial Surgery, 42, 494500. http://dx.doi.org/10.1016/j.bjoms.2004.06.013

[9] Kruse, A.L. and Gratz, K.W. (2009) Cervical Metastases of Squamous Cell Carcinoma of the Maxilla: A Retrospective Study of 9 Years. Head \& Neck Oncology, 1, 28. http://dx.doi.org/10.1186/1758-3284-1-28

[10] Montes, D.M. and Schmidt, B.L. (2008) Oral Maxillary Squamous Cell Carcinoma: Management of the Clinically Negative Neck. Journal of Oral and Maxillofacial Surgery, 66, 762-766. http://dx.doi.org/10.1016/j.joms.2007.12.017

[11] Simental Jr., A.A., Johnson, J.T. and Myers, E.N. (2006) Cervical Metastasis from Squamous Cell Carcinoma of the Maxillary Alveolus and Hard Palate. Laryngoscope, 116, 1682-1684.

http://dx.doi.org/10.1097/01.mlg.0000233607.41540.28

[12] Dalal, A.J. and McLennan, A.S. (2013) Cervical Metastases from Maxillary Squamous Cell Carcinoma: Retrospective Analysis and Review of the Literature. British Journal of Oral and Maxillofacial Surgery, 51, 702-706. http://dx.doi.org/10.1016/j.bjoms.2013.08.011

[13] Lin, H.W. and Bhattacharyya, N. (2009) Survival Impact of Nodal Disease in Hard Palate and Maxillary Alveolus Cancer. Laryngoscope, 119, 312-315. http://dx.doi.org/10.1002/lary.20054

[14] Poeschl, P.W., Seemann, R., Czembirek, C., Russmueller, G., Sulzbacher, I., Selzer, E., Nuhic, D. and Ewers, R. (2012) Impact of Elective Neck Dissection on Regional Recurrence and Survival in cN0 Staged Oral Maxillary Squamous Cell Carcinoma. Oral Oncology, 48, 173-178. http://dx.doi.org/10.1016/j.oraloncology.2011.09.006

[15] Hiratsuka, H., Miyakawa, A., Nakamori, K., Kido, Y., Sunakawa, H. and Kohama, G. (1997) Multivariate Analysis of Occult Lymph Node Metastasis as a Prognostic Indicator for Patients with Squamous Cell Carcinoma of the Oral Cavity. Cancer, 80, 351-356. http://dx.doi.org/10.1002/(SICI)1097-0142(19970801)80:3<351::AID-CNCR1>3.0.CO;2-V

[16] Kurokawa, H., Yamashita, Y., Takeda, S., Zhang, M., Fukuyama, H. and Takahashi, T. (2002) Risk Factors for Late Cervical Lymph Node Metastases in Patients with Stage I or II Carcinoma of the Tongue. Head \& Neck, 24, 731-736. http://dx.doi.org/10.1002/hed.10130

[17] Sparano, A., Weinstein, G., Chalian, A., Yodul, M. and Weber, R. (2004) Multivariate Predictors of Occult Neck Metastasis in Early Oral Tongue Cancer. Otolaryngology-Head and Neck Surgery, 131, 472-476. http://dx.doi.org/10.1016/j.otohns.2004.04.008

[18] Wallwork, B.D., Anderson, S.R. and Coman, W.B. (2007) Squamous Cell Carcinoma of the Floor of the Mouth: Tumour Thickness and the Rate of Cervical Metastasis. ANZ Journal of Surgery, 77, 761-764. http://dx.doi.org/10.1111/j.1445-2197.2007.04219.x 
[19] Beltramini, G.A., Massarelli, O., Demarchi, M., Copelli, C., Cassoni, A., Valentini, V., Tullio, A., Gianni, A.B., Sesenna, E. and Baj, A. (2012) Is Neck Dissection Needed in Squamous-Cell Carcinoma of the Maxillary Gingiva, Alveolus, and Hard Palate? A Multicentre Italian Study of 65 Cases and Literature Review. Oral Oncology, 48, 97-101. http://dx.doi.org/10.1016/j.oraloncology.2011.08.012

[20] Montes, D.M., Carlson, E.R., Fernandes, R., Ghali, G.E., Lubek, J., Ord, R., Bell, B., Dierks, E. and Schmidt, B.L. (2011) Oral Maxillary Squamous Carcinoma: An Indication for Neck Dissection in the Clinically Negative Neck. Head \& Neck, 33, 1581-1585. http://dx.doi.org/10.1002/hed.21631

[21] Haddadin, K.J., Soutar, D.S., Oliver, R.J., Webster, M.H., Robertson, A.G. and MacDonald, D.G. (1999) Improved Survival for Patients with Clinically T1/T2, N0 Tongue Tumors Undergoing a Prophylactic Neck Dissection. Head \& Neck, 21, 517-525. http://dx.doi.org/10.1002/(SICI)1097-0347(199909)21:6<517::AID-HED4>3.0.CO;2-C

[22] Kligerman, J., Lima, R.A., Soares, J.R., Prado, L., Dias, F.L., Freitas, E.Q. and Olivatto, L.O. (1994) Supraomohyoid Neck Dissection in the Treatment of T1/T2 Squamous Cell Carcinoma of Oral Cavity. American Journal of Surgery, 168, 391-394. http://dx.doi.org/10.1016/S0002-9610(05)80082-0

[23] Weiss, M.H., Harrison, L.B. and Isaacs, R.S. (1994) Use of Decision Analysis in Planning a Management Strategy for the Stage N0 Neck. JAMA Otolaryngology-Head and Neck Surgery, 120, 699-702. http://dx.doi.org/10.1001/archotol.1994.01880310005001 
Scientific Research Publishing (SCIRP) is one of the largest Open Access journal publishers. It is currently publishing more than 200 open access, online, peer-reviewed journals covering a wide range of academic disciplines. SCIRP serves the worldwide academic communities and contributes to the progress and application of science with its publication.

Other selected journals from SCIRP are listed as below. Submit your manuscript to us via either submit@scirp.org or Online Submission Portal.
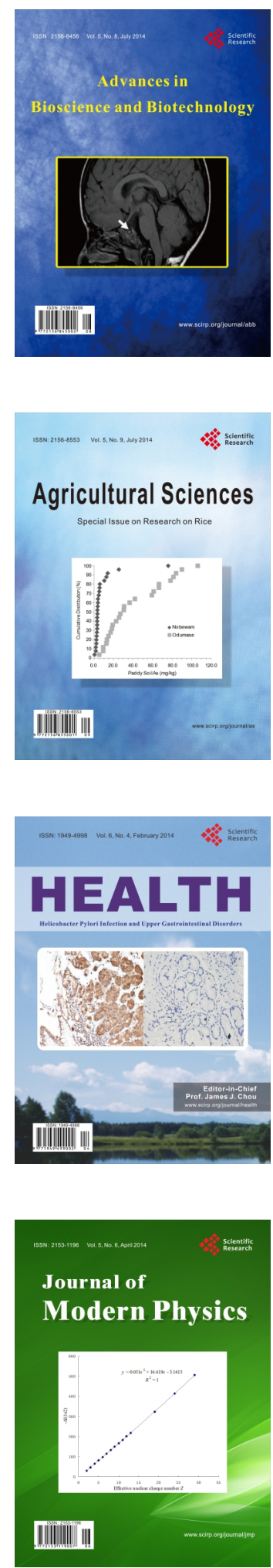
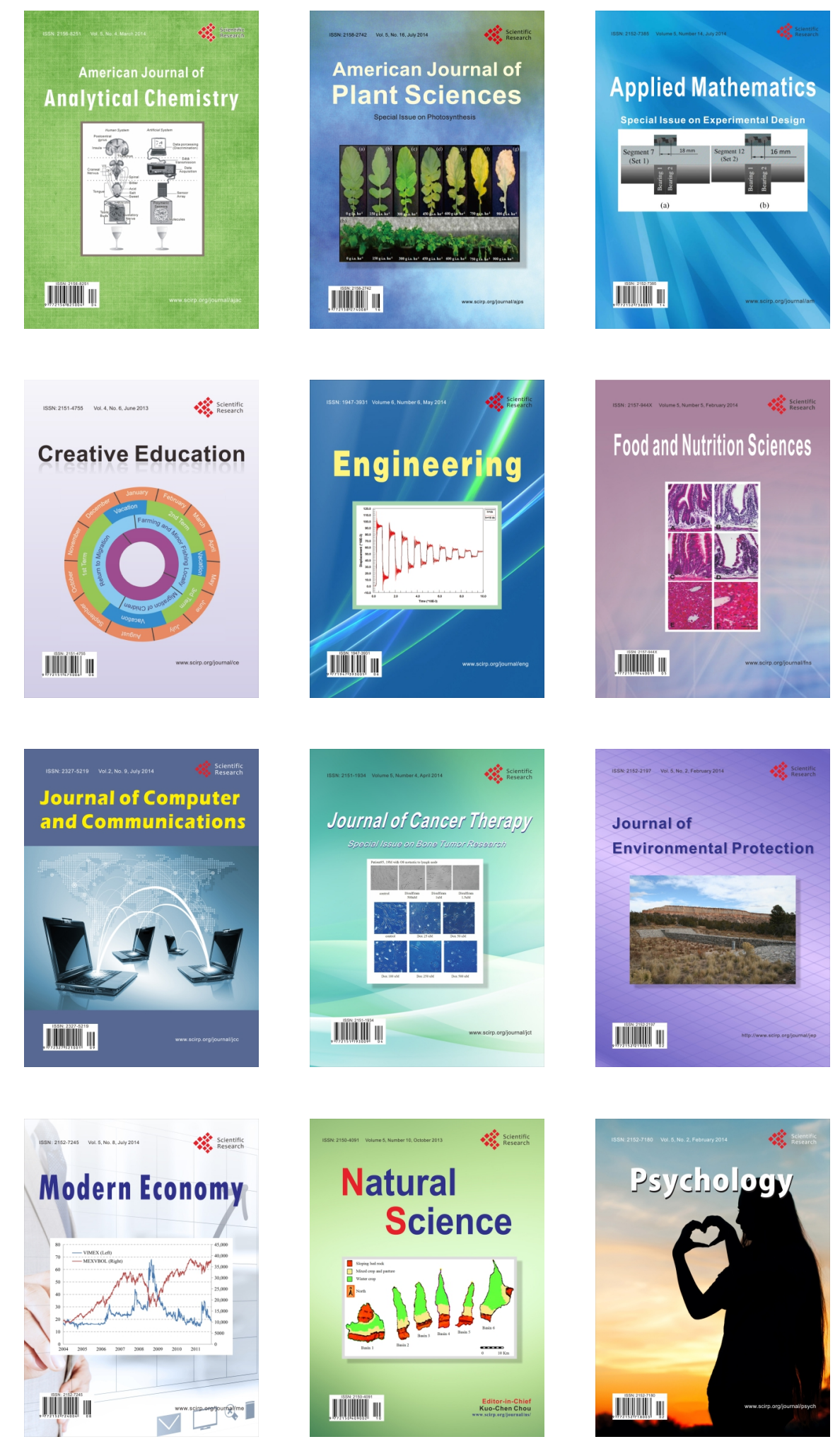